\title{
Regulation of Aromatic Metabolism in the Fungi: Metabolic Control of the 3-Oxoadipate Pathway in the Yeast Rhodotorula mucilaginosa
}

\author{
By K. A. COOK AND R. B. CAIN \\ Biological Laboratories, University of Kent, Canterbury $\mathrm{CT}_{2}{ }_{7 \mathrm{NJ}}$, Kent
}

(Received 6 May 1974; revised 20 June 1974)

\begin{abstract}
SUMMARY
The metabolic control of the protocatechuate branch of the 3-oxoadipate pathway in Rhodotorula mucilaginosa was examined and the specific inducers identified using appropriately blocked mutants. Three successive inductive events permitted the synthesis of the five enzymes converting $p$-hydroxybenzoate to 3-oxoadipyl-CoA: the independent induction of 4-hydroxybenzoate 3-monooxygenase by its own specific substrate, the independent induction of protocatechuate 3,4-dioxygenase by either protocatechuate or $p$-hydroxybenzoate, and finally the co-ordinate induction of 3-carboxymuconate cyclase, 3 -carboxymuconolactone hydrolase and 3-oxoadipate CoA-transferase by either protocatechuate or $p$-hydroxybenzoate. Evidence is presented which suggests that $R$. mucilaginosa is unable to metabolize catechol or its usual precursors, and the significance of this is discussed in relation to control of the protocatechuate branch and the differing control mechanisms governing the synthesis of enzymes of the 3-oxoadipate pathway in other fungi and bacteria.
\end{abstract}

\section{INTRODUCTION}

The 3-oxoadipate pathway (Fig. I) serves in many aerobic bacteria to transform catechol, protocatechuate and their respective precursors to succinate and acetyl-CoA. The regulation of the enzymes operative in this pathway has been extensively investigated in a number of species of Pseudomonas (Ornston, I966a; Kemp \& Hegeman, I968; Stanier, 1968; RobertGero, Poiret \& Stanier, I969) and in Moraxella calcoacetica (Cánovas \& Stanier, 1967), Alcaligenes eutrophus (Johnson \& Stanier, 1971) and several Nocardia species (Rann \& Cain, 1969, I973).

A general survey of the routes utilized by fungi for the catabolism of aromatic compounds (Cain, Bilton \& Darrah, I968) confirmed the widespread existence of the 3-oxoadipate pathway within this group. In all the fungal genera examined the subsequent metabolism of the ring cleavage product, 3-carboxymuconate, proceeded through 3-carboxymuconolactone rather than through the 4 -substituted isomer characteristic of the bacteria, confirming an earlier observation in Neurospora crassa (Gross, Gafford \& Tatum, 1956). The metabolic control of the 3-oxoadipate pathway in fungi, however, is not well documented, although preliminary studies have indicated similarities in the extent of co-ordinate control exercised in both fungi and bacteria (Cain, r 969; Halsall, Darrah \& Cain, 1969).

This paper examines the metabolic control of the protocatechuate branch of the 3-oxoadipate pathway in the yeast Rhodotorula mucilaginosa. The physiological specificity of the control of the pathway and the extent of co-ordinate enzyme induction have been studied, and an attempt has been made to identify the operative inducer molecules using specifically blocked mutants. 
Protocatechuate branch

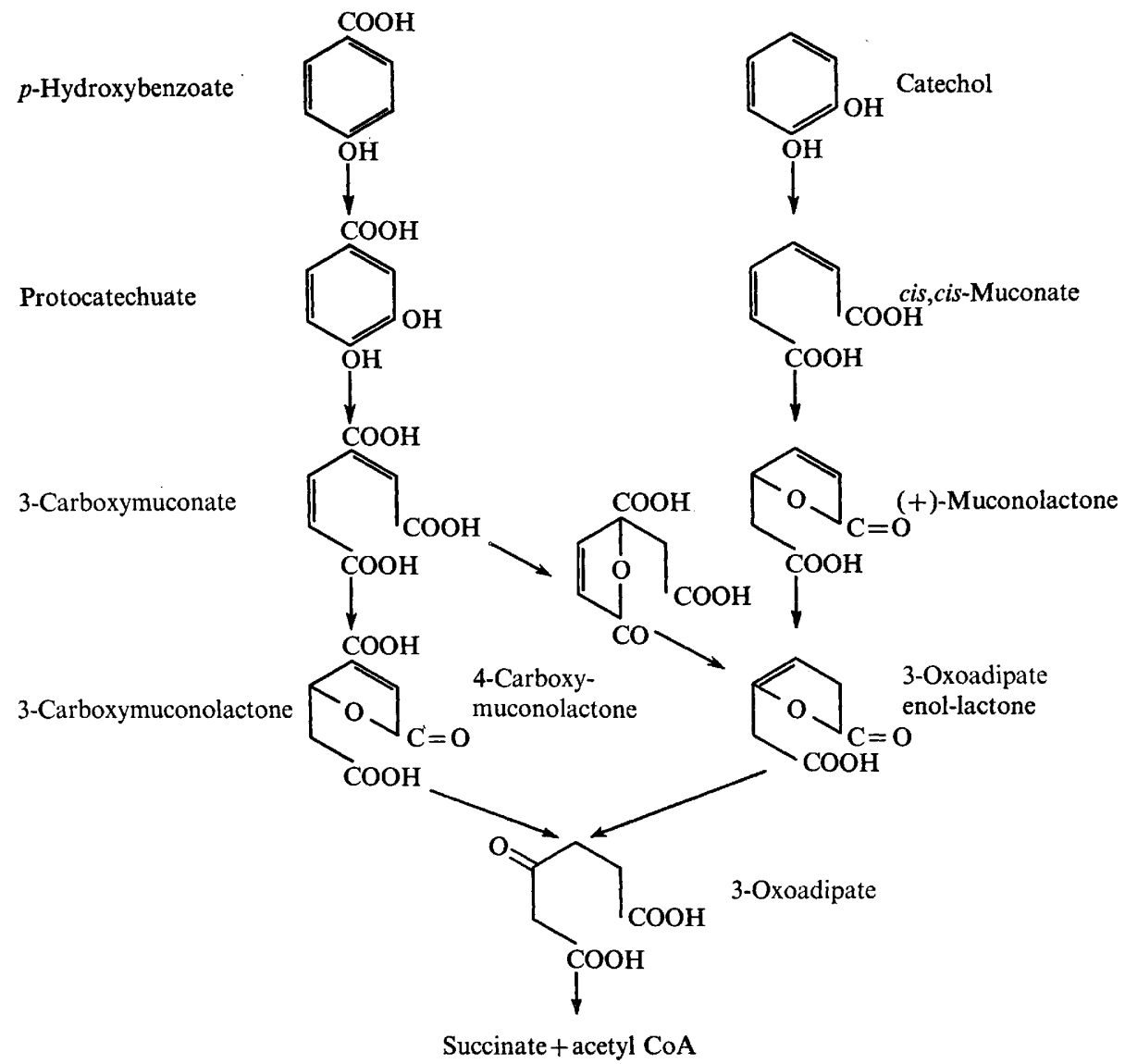

Fig. I. The 3-oxoadipate pathway in fungi and bacteria. The metabolism of protocatechuate via 4-carboxymuconolactone is characteristic of the bacteria. In the fungi metabolism proceeds via 3-carboxymuconolactone.

\section{METHODS}

Organisms. Wild-type $R$. mucilaginosa was isolated as an aerial contaminant of $p$-hydroxybenzoate medium (Cain et al. 1968) and identified at the Brewing Industry Research Foundation, Nutfield, Surrey. Mutants were isolated after treatment of the wild-type strain with $N$-methyl- $N^{\prime}$-nitro- $N$-nitrosoguanidine followed by selection with the antifungal antibiotic nystatin (Cook, 1974).

Media. The composition of the mineral salts base and the use of glucose, $p$-hydroxybenzoate and protocatechuate as carbon sources were as described by Cook (1974). Anthranilate, catechol, salicylate, guaiacol and veratrole were added directly to the mineral salts base at the required concentrations. The medium was adjusted to $\mathrm{pH} 5.5$ and sterilized by filtration. Media will subsequently be referred to by the name of the carbon source(s) which they contained.

Growth and maintenance of organisms. All strains were maintained by monthly subculture on ro mM-glucose slopes at $30^{\circ} \mathrm{C}$, and stored at $4{ }^{\circ} \mathrm{C}$. Liquid cultures were grown in a volume of $\mathrm{I} 1$ in 21 capacity Erlenmeyer flasks and incubated at $30^{\circ} \mathrm{C}$ on a rotary shaker 
(Mark 3, L.H. Engineering Co., Stoke Poges, Buckinghamshire) operated at $140 \mathrm{rev} . / \mathrm{min}$. Growth was monitored spectrophotometrically using a Unicam SP 500 spectrophotometer (Pye Unicam Ltd, Cambridge) and the extinction at $600 \mathrm{~nm}$ related to cell numbers obtained by direct counting. The relationship between $E_{600}$ and cell numbers was linear with suspensions containing up to $8 \times 10^{6}$ cells $/ \mathrm{ml}$.

Mutagenesis, selection and characterization of mutants. Induction and selection of mutants and determination of their nutritional requirements have been described previously (Cook, 1974). The site of the enzymic lesion in mutants which had lost the ability to grow with aromatic carbon sources was determined as follows: mutants were grown in liquid media at the expense of Io mM-glucose in the presence of $20 \mathrm{~mm}$ - $p$-hydroxybenzoate, and the glucose concentration in the culture filtrates monitored until 60 to $70 \%$ had been utilized (approximately $\mathrm{I} 6$ to $\mathrm{I} 8 \mathrm{~h}$ ) when organisms were harvested by centrifugation and cell-free extracts prepared.

Preparation of cell-free extracts. Exponentially growing organisms were harvested from I 1 of medium by centrifuging at $2000 \mathrm{~g}$ (Mistral 6L refrigerator centrifuge, MSE Ltd, London) for $20 \mathrm{~min}$, washed with chilled tris- $\mathrm{HCl}$ buffer $(0.05 \mathrm{M}, \mathrm{pH} \mathrm{7.5)}$, and recentrifuged at $38000 \mathrm{~g}$ (MSE Highspeed $\mathrm{I} 8$ refrigerator centrifuge) for Io min. All centrifuging was done at $4{ }^{\circ} \mathrm{C}$ and cell pellets were stored at $-30{ }^{\circ} \mathrm{C}$ if not required immediately.

Frozen or freshly washed cell pellets were suspended in an approximately equal volume of tris- $\mathrm{HCl}$ buffer $(0.05 \mathrm{M}, \mathrm{pH} 7.5)$ and sonically disrupted for 3 min with a $150 \mathrm{~W}$ ultrasonic disintegrator (MSE Ltd). The sonicator probe was prechilled and sonication performed in $30 \mathrm{~s}$ bursts with intermittent cooling to $5{ }^{\circ} \mathrm{C}$ in an ice/salt bath. The sonicated suspension was centrifuged at $200000 \mathrm{~g}$ for $2 \mathrm{~h}$ in the IO $\times$ I0 $\mathrm{ml}$ head (No. 59I I3) of an MSE automatic Superspeed 50 TC refrigerator centrifuge. The pale yellow supernatant was decanted and used immediately for the measurement of enzyme activities.

Enzyme assays. All enzymes were assayed spectrophotometrically at $30{ }^{\circ} \mathrm{C}$ in quartz cuvettes of Io mm light path with a Unicam SP $800 \mathrm{~A}$ recording spectrophotometer (Pye Unicam Ltd) fitted with a Unicam AR 25 series slave recorder and a constant temperature cuvette holder through which water was circulated from a constant temperature bath (Model SB I, Grant Instruments, Cambridge, Ltd). Unless otherwise stated, a unit of enzyme activity was defined as the amount of enzyme catalysing the disappearance of I $\mu \mathrm{mol}$ substrate/min under the conditions of the assay. The procedures described below are modifications of those used by Cain et al. (1968).

Throughout this work the activities of enzymes of the 3-oxoadipate pathway are expressed relative to those of glucose 6-phosphate dehydrogenase which had a constant specific activity under the various experimental conditions employed (Table I). Activity ratios have been similarly utilized in the study of repressible enzyme systems from both $N$. crassa (Cook \& Sorger, 1969) and Coprinus lagopus (North \& Lewis, 1973), and the advantages of using such a system of measurement lie in the speed, accuracy and sensitivity with which glucose 6-phosphate dehydrogenase may be measured.

The activity ratio employed here was defined as

$$
\text { activity ratio }=\frac{\text { units of enzyme } / \mathrm{ml}}{\text { units of glucose } 6 \text {-phosphate dehydrogenase } / \mathrm{ml}} \cdot
$$

Enzymes were assayed as follows:

(i) 4-Hydroxybenzoate 3-mono-oxygenase [4-hydroxybenzoate, NADH: oxygen oxidoreductase ( 3 hydroxylating), EC. I. I4.13.2] was determined by measuring the substratedependent oxidation of $\mathrm{NADH}$ at $340 \mathrm{~nm}\left(\epsilon_{340}=6220\right)$. The reaction mixture contained 
Table I. Effect of various carbon sources on the specific activity of glucose 6-phosphate dehydrogenase in extracts of wild-type $R$. mucilaginosa

Organisms were grown to exponential phase on the indicated carbon sources, harvested by centrifugation and extracts prepared by sonication. Carbon sources were used at a concentration of $10 \mathrm{~mm}$ unless otherwise stated. The specific activities shown represent the average of determinations on extracts prepared from at least four different cultures grown on the appropriate substrate, and standard errors of the mean are indicated.

Substrate

Glucose

Glucose $+p$-hydroxybenzoate*

$p$-Hydroxybenzoate

Protocatechuate

Benzoate
Glucose 6-phosphate dehydrogenase (units/mg protein)

* Io mM-glucose + 20 mm-p-hydroxybenzoate.

( $\mu \mathrm{mol}$ ): tris- $\mathrm{HCl}, \mathrm{pH} 7.5, \mathrm{I} 50 ; \mathrm{FAD}, 0.02 ; \mathrm{NADH}, \mathrm{I} \cdot 0 ; p$-hydroxybenzoate, $\mathrm{I} \cdot 0$; extract and water in a final volume of $3.0 \mathrm{ml}$. The reaction was initiated by the addition of the aromatic substrate and the rate of NADH oxidation corrected for endogenous oxidation in its absence; the reference cuvette contained all reagents except NADH. The oxidation of I $\mu \mathrm{mol}$ of $\mathrm{NADH}$ was equivalent to the hydroxylation of I $\mu \mathrm{mol}$ of $p$-hydroxybenzoate.

(ii) Protocatechuate 3,4-dioxygenase [protocatechuate: oxygen 3,4-oxidoreductase (decyclizing), EC. I.I3.II.3] was assayed by following the decrease in absorbance of protocatechuate at $290 \mathrm{~nm}\left(\epsilon_{290}=3890\right)$. The product of the reaction, 3-carboxymuconate $\left(\epsilon_{290}=1590\right)$, did not accumulate when crude extracts were used. The reaction mixture contained $(\mu \mathrm{mol})$ : tris- $\mathrm{HCl}, \mathrm{pH} 7.5,150$; protocatechuate, 0.5 ; extract and water to a final volume of $3.0 \mathrm{ml}$. The reference cuvette lacked the substrate which was used to initiate the reaction.

(iii) 3-Carboxy-cis,cis-muconate cyclase [3-carboxymuconolactone lyase (decyclizing), EC. 5.5.I.5] was determined by following the decrease in absorbance of the substrate at $260 \mathrm{~nm}\left(\epsilon_{260}=8 \mathrm{I} 50\right)$. The product of this reaction (3-carboxymuconolactone) and subsequent products did not absorb appreciably at this wavelength. The reaction mixture contained $(\mu \mathrm{mol})$ : histidine-HCl buffer, $\mathrm{pH} \mathrm{6.0,250;3-carboxy-cis,cis-muconate,} \mathrm{I} \cdot 0$; extract and water to $3.0 \mathrm{ml}$. The reaction was initiated by the addition of the substrate which was absent from the reference cuvette.

(iv) 3-Carboxymuconolactone hydrolase (EC. 3. I. I.-) was followed by observing the decrease in substrate absorbance at $230 \mathrm{~nm}\left(\epsilon_{230}=8500\right)$. The reaction mixture contained $(\mu \mathrm{mol})$ : tris- $\mathrm{HCl}$ buffer, $\mathrm{pH} 7.5,150 ; 3$-carboxymuconolactone, 0.75 ; extract and water to a final volume of $3.0 \mathrm{ml}$. The reaction was initiated by the addition of 3 -carboxymuconolactone to the test cuvette.

(v) 3-Oxoadipate CoA-transferase (succinyl-CoA: 3-oxoadipate CoA-transferase, EC. 2.8.3.6) was measured by a variation of the procedure in Katagiri \& Hayaishi (I957), following the increase in absorbance at $305 \mathrm{~nm}$ due to the formation of 3-oxoadipyl-CoA. The absorbance of 3-oxoadipyl-CoA at this wavelength was low, but the enzyme could be assayed reliably provided that small amounts of enzyme were used and that absorbance changes recorded on the spectrophotometer were expanded tenfold (Cánovas \& Stanier, 1967). The reaction mixture contained ( $\mu \mathrm{mol})$ : tris- $\mathrm{HCl}$ buffer, $\mathrm{pH} 7 \cdot 6,100 ; \mathrm{MgCl}_{2}$, I0; succinyl-CoA, 0.5; 3-oxoadipate, 25; extract and water to a final volume of $\mathrm{I} \cdot 0 \mathrm{ml}$. The 
reference cuvette lacked 3-oxoadipate and succinyl-CoA. The reaction was initiated by the addition of 3-oxoadipate and, when no further change in absorbance at $305 \mathrm{~nm}$ was observed, by succinyl-CoA. One unit of activity was defined as the amount of enzyme producing an absorbance increase of $\mathrm{I} \cdot 0 / \mathrm{min}$ at $305 \mathrm{~nm}$ (Cánovas \& Stanier, 1967).

(vi) Glucose 6-phosphate dehydrogenase (D-glucose 6-phosphate: NADP ${ }^{+}$I-oxido- $^{-}$ reductase, EC. I . I . I .49) was measured as described by Glock \& McLean (I 953).

(vii) Catechol I,2-dioxygenase [catechol: oxygen I,2-oxidoreductase (decyclizing), EC. I.I3.II.I], muconate cycloisomerase [4-carboxymethyl-4-hydroxyisocrotonolactone lyase (decyclizing), EC. 5.5.I I I] and (+)-muconolactone $\Delta$-isomerase $[(+)-4$-hydroxy-4-carboxymethylisocrotonolactone- $\Delta^{2}-\Delta^{3}$-isomerase, EC. 5.3.3.4] were assayed as described by Ornston (I966b).

Chemical and physical determinations. Protein was determined by the Biuret method of Gornall, Bardawill \& David (1949) using bovine serum albumin (fraction V; Sigma) as standard. Glucose was determined colorimetrically by the GOD-Perid method using a reagent kit (The Boehringer Corp., London, Ltd).

$p$-Hydroxybenzoate, protocatechuate, catechol, anthranilate, veratrole, guaiacol and salicylate present in culture filtrates were estimated spectrophotometrically at $\mathrm{pH} 5.5$ from their absorption maxima at $245,290,270,310,270,270$ and $294 \mathrm{~nm}$ respectively.

Syntheses. 3-Oxoadipic acid was synthesized by the method of Bardhan (1936) and 3carboxy-cis,cis-muconate (trisodium salt) by the method of Ainsworth \& Kirby (I968). 3-Carboxymuconolactone was synthesized from 3-carboxy-cis,cis-muconate enzymically as described by Cain et al. (1968). Succinyl-CoA was prepared from CoA and succinic anhydride essentially by the method of Simon \& Shemin (1953) and assayed by the hydroxamate method of Lipmann \& Tuttle (1945) as described by Stadtman (1957).

\section{RESULTS}

The catechol branch of the 3-oxoadipate pathway

Enzymes specific to the catechol branch of the 3-oxoadipate pathway (catechol I,2dioxygenase, muconate cycloisomerase and $(+)$-muconolactone $\Delta$-isomerase) have been demonstrated in extracts of a number of fungal species grown on equimolar mixtures of glucose and either catechol, anthranilate or phenol (Cain et al. 1968; Halsall, 1971). Glucose was incorporated into the media as none of these aromatic substrates was able to support adequate growth when supplied as sole carbon source (Halsall, I97I). In R. mucilaginosa, synthesis of the enzymes specific to the catechol pathway could not be elicited even after growth in the presence of non-toxic amounts of catechol (Halsall, 197I). In an attempt to demonstrate the existence of the catechol pathway in $R$. mucilaginosa, wild-type organisms were tested for their ability either to utilize or to co-oxidize in the presence of glucose a number of aromatic compounds which, chemically, appeared likely precursors of catechol. Organisms from an exponential culture of the wild-type strain on glucose were harvested by centrifugation, washed in saline $(0.85 \%, \mathrm{w} / \mathrm{v}, \mathrm{NaCl}$ solution) and used to inoculate media containing either catechol, salicylate, anthranilate, veratrole or guaiacol as carbon sources. The initial cell density in each medium was adjusted to $5 \times 10^{5}$ organisms $/ \mathrm{ml}$ and the cultures incubated at $30^{\circ} \mathrm{C}$ for a period of 7 days. No increase in cell density, above that due to residual growth of the inoculum, was observed during this time, suggesting that none of the aromatic compounds tested was capable of supporting growth of $R$. mucilaginosa under the conditions used.

Although these compounds did not support growth when supplied to the organism as a 
Table 2. Influence of various growth substrates on the activities of enzymes of the 3-oxoadipate pathway in extracts of wild-type $R$. mucilaginosa

Organisms were grown to exponential phase at the expense of the substrate indicated, harvested by centrifugation and extracts prepared by sonication. All substrates were used at a concentration of $10 \mathrm{~mm}$. The activity ratios shown represent the average of determinations on extracts prepared from at least four different cultures grown on the indicated substrate and errors are presented as standard error of the mean.

\begin{tabular}{|c|c|c|c|c|c|}
\hline Region of pathway & Enzyme & Glucose & $\begin{array}{l}p \text {-Hydroxy- } \\
\text { benzoate }\end{array}$ & $\begin{array}{l}\text { Proto- } \\
\text { catechuate }\end{array}$ & Benzoate \\
\hline \multirow[t]{4}{*}{$\begin{array}{l}\text { Protocatechuate } \\
\text { branch }\end{array}$} & $\begin{array}{l}\text { 4-Hydroxybenzoate } \\
\text { 3-monoxygenase }\end{array}$ & $<0.006$ & $0.87 \pm 0.06$ & $<0.006$ & $0.58 \pm 0.03$ \\
\hline & $\begin{array}{l}\text { Protocatechuate } \\
\text { 3,4-dioxygenase }\end{array}$ & $0.03 \pm 0.003$ & $0.65 \pm 0.05$ & $0.61 \pm 0.04$ & $0.62 \pm 0.05$ \\
\hline & $\begin{array}{l}\text { 3-Carboxymuconate } \\
\text { cyclase }\end{array}$ & $1.03 \pm 0.05$ & $2 \cdot 44 \pm 0.17$ & $2 \cdot 76 \pm 0.04$ & $I \cdot 94 \pm 0.06$ \\
\hline & $\begin{array}{l}\text { 3-Carboxymuconolactone } \\
\text { hydrolase }\end{array}$ & $0.19 \pm 0.02$ & $I \cdot 90 \pm 0.06$ & $2 \cdot 20 \pm 0.15$ & $I \cdot 93 \pm 0.06$ \\
\hline \multirow[t]{3}{*}{ Catechol branch } & Catechol I,2-dioxygenase & $<0.002^{*}$ & $<0.002$ & $<0.002$ & $<0.002$ \\
\hline & Muconate cycloisomerase & $<0.002$ & $<0.002$ & $<0.002$ & $<0.002$ \\
\hline & $\begin{array}{c}\text { Muconolactone } \\
\Delta \text {-isomerase }\end{array}$ & $<0.02$ I & $<0.021$ & $<0.021$ & $<0.02 I$ \\
\hline Both branches & $\begin{array}{l}\text { 3-Oxoadipate CoA- } \\
\text { transferase }\end{array}$ & $0.19 \pm 0.01$ & $2 \cdot 32 \pm 0 \cdot 16$ & $I \cdot 79 \pm 0.08$ & $-\dagger$ \\
\hline
\end{tabular}

sole carbon source, it was possible that they could be metabolized in the presence of a readily utilizable carbon source, e.g. glucose, as occurs in several other fungi (Halsall, I97I). When 2 mM-glucose was added as a supplement to such aromatic media the glucose was completely utilized after $20 \mathrm{~h}$ incubation with $R$. mucilaginosa at $30^{\circ} \mathrm{C}$, but spectrophotometric analysis of the culture filtrates indicated that none of the aromatic compounds were metabolized even after a period of $70 \mathrm{~h}$.

The failure of $R$. mucilaginosa to metabolize catechol or its putative precursors suggested that: (i) the organism was impermeable to the substrates used, (ii) none of the substrates tested were in fact physiological precursors of intermediates of the catechol pathway, or (iii) no functional pathway for the catabolism of catechol or its precursors exists in $R$. mucilaginosa.

\section{Patterns of induction of enzymes of the 3-oxoadipate pathway in wild-type}

\section{R. mucilaginosa}

Inductive patterns with respect to enzymes of the 3-oxoadipate pathway were determined on extracts of the wild-type strain after exponential growth at the expense of $p$-hydroxybenzoate, protocatechuate and benzoate. Basal, uninduced levels of these enzymes were determined on extracts of cells grown with glucose (Table 2). The three enzymes specific to the catechol branch of the pathway (catechol 1,2-dioxygenase, muconate cycloisomerase and $(+)$-muconolactone $\Delta$-isomerase) were undetectable in any of the extracts examined, in agreement with results obtained with a variety of different fungal species (Cain et al. I968). The failure of benzoate to elicit synthesis of the enzymes of the catechol pathway was due to its hydroxylation to $p$-hydroxybenzoate and subsequent metabolism via protocatechuate (Halsall et al. 1969; Halsall, I97I). 


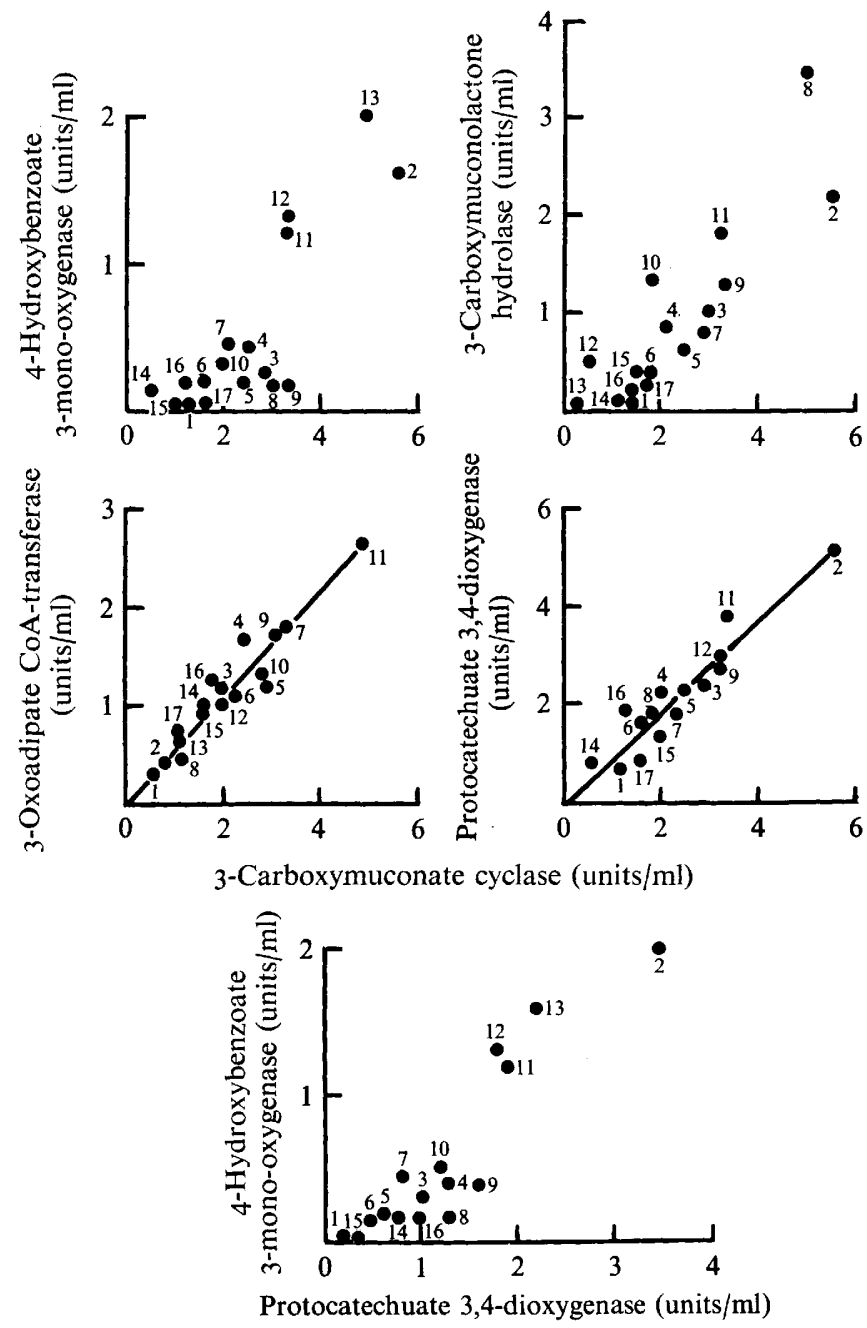

Fig. 2. Relative activities of enzymes of the protocatechuate pathway in extracts of wild-type $R$. mucilaginosa. The relative activities of 4 -hydroxybenzoate 3-mono-oxygenase, 3-carboxymuconolactone hydrolase, 3-oxoadipate CoA-transferase, protocatechuate 3,4-dioxygenase and 3-carboxymuconate cyclase, were determined in extracts of wild-type $R$. mucilaginosa prepared from cells grown on media containing the following carbon sources: (1) $10 \mathrm{~mm}$-glucose; (2) $10 \mathrm{~mm}-\mathrm{p}$-hydroxybenzoate; (3) Io mM-glucose and $20 \mathrm{~mm}-p$-hydroxybenzoate; (4) Io mM-glucose and Io mM- $p$ hydroxybenzoate; (5) $20 \mathrm{~mm}$-glucose and $10 \mathrm{~mm}$ - $p$-hydroxybenzoate; (6) $21 \mathrm{~mm}$-glucose and 7 mM-p-hydroxybenzoate; (7) 25 mM-glucose and 5 mM-p-hydroxybenzoate; (8) 30 mm-glucose and I mm-p-hydroxybenzoate; (9) $30 \mathrm{~mm}$-glucose and $0.5 \mathrm{~mm}$ - -hydroxybenzoate; (10) $5 \mathrm{~mm}$ glucose and Io mM-p-hydroxybenzoate; (II) $2.5 \mathrm{~mm}$-glucose and $10 \mathrm{~mm}$-p-hydroxybenzoate; (I 2) $1 \mathrm{~mm}$-glucose and Io $\mathrm{mm}$-p-hydroxybenzoate; (13) I mm-glucose and $20 \mathrm{~mm}$-p-hydroxybenzoate; (I4) Io mm-benzoate; (I5) Io mm-glucose and Io mm-protocatechuate; (I6) Io mm-glucose and Io mm-benzoate; (17) 10 mM-protocatechuate.

After the yeast had been grown on glucose, extracts showed considerable variation in the basal uninduced activities of the enzymes of the protocatechuate pathway (Table 2). The first enzyme operative in the pathway (4-hydroxybenzoate 3-mono-oxygenase) was undetectable in extracts of glucose-grown cells, while protocatechuate 3,4-dioxygenase and 3-oxoadipate CoA-transferase were present at low but detectable levels, representing about 
Table 3. Enzyme activities in strains of $R$. mucilaginosa specifically blocked in the protocatechuate pathway

Organisms were grown to exponential phase on glucose medium, harvested by centrifugation, washed with physiological saline, and transferred to media containing Io mm-glucose in the presence or absence of the inducer, $20 \mathrm{~mm}$ - $p$-hydroxybenzoate. The initial cell density in each medium was adjusted to $5 \times 10^{5} / \mathrm{ml}$ and cultures incubated at $30^{\circ} \mathrm{C}$. The concentration of glucose in the culture filtrates was estimated colorimetrically throughout the growth cycle and cultures were harvested when $65 \%$ of the glucose had been utilized. The activity ratios shown represent the average of determinations on extracts prepared from three different cultures grown as indicated above.

\begin{tabular}{|c|c|c|c|c|c|c|c|c|c|c|}
\hline \multirow[b]{3}{*}{ Enzyme } & \multicolumn{10}{|c|}{ Activity ratio } \\
\hline & \multicolumn{5}{|c|}{ Inducer present, on strain: } & \multicolumn{5}{|c|}{ Inducer absent, on strain: } \\
\hline & wT & PHBI & PHB3 & PCA33 & PCA4O & wT & PHB I & PHB3 & PCA33 & PCA5O \\
\hline $\begin{array}{l}\text { 4-Hydroxybenzoate } \\
\text { 3-mono-oxygenase } \\
\text { Protocatechuate }\end{array}$ & 0.27 & $<0.006^{*}$ & $<0.006$ & 0.09 & 0.22 & $<0.006$ & $6<0.006$ & $<0.006$ & $<<0.006$ & $<0.006$ \\
\hline $\begin{array}{l}\text { 3,4-dioxygenase } \\
\text { 3-Carboxymuconate }\end{array}$ & $0 \cdot 31$ & 0.38 & 0.49 & $<0.009^{*}$ & $<0.009$ & 0.03 & $<0.009$ & 0.03 & $<0.009$ & $<0.009$ \\
\hline $\begin{array}{l}\text { cyclase } \\
\text { 3-Carboxymucono- }\end{array}$ & $2 \cdot 20$ & 3.00 & $3 \cdot 10$ & $\mathrm{I} \cdot 99$ & $2 \cdot 60$ & $I \cdot 03$ & 0.60 & $\mathrm{I} \cdot 20$ & I $\cdot$ IO & I 15 \\
\hline lactone hydrolase & $1 \cdot 17$ & I 15 & $\mathrm{I} \cdot 20$ & $I \cdot 30$ & $1 \cdot 55$ & 0.19 & 0.09 & 0.18 & 0.17 & 0.37 \\
\hline
\end{tabular}

4 and $8 \%$, respectively, of the levels obtained with fully induced cells. The two other enzymes uniquely associated with the protocatechuate pathway (3-carboxymuconate cyclase and 3-carboxymuconolactone hydrolase) were present in glucose-grown cells at approximately 40 and $10 \%$, respectively, of the levels observed with fully induced cells. This phenomenon of high uninduced enzyme levels in extracts has been observed previously in other fungi (Gross et al. 1956; Halsall, I97I), though rarely as high as $40 \%$.

The enzyme activities observed in extracts of cells induced on different aromatic carbon sources were remarkably similar and in no case were enzymes specific to the catechol pathway detectable. Accordingly, the inductive responses resulting from growth of the wild-type strain on $p$-hydroxybenzoate, protocatechuate and benzoate indicate a high degree of physiological specificity.

The absence of induction of significant 4-hydroxybenzoate 3-mono-oxygenase activity by protocatechuate suggested that this enzyme was substrate-induced and hence independently regulated, although the data in Table 2 do not rule out benzoate as a possible inducer in addition to $p$-hydroxybenzoate.

\section{The extent of co-ordinacy of enzymes of the protocatechuate pathway}

Enzymes which are co-ordinately induced and repressed are, by definition, formed in constant relative amounts under all conditions. Thus while their absolute activities may vary under differing conditions of induction their relative activities always remain constant. All of the enzymes of the protocatechuate pathway were subject to varying degrees of catabolite repression by glucose. Hence by growing organisms on varying ratios of glucose and aromatic substrate it was possible to achieve a reduction in the levels of the enzymes of this pathway, and thus to examine the extent of co-ordinacy (Ornston, I966a; Cànovas \& Stanier, 1967). The results of a series of experiments performed with $p$-hydroxybenzoate, protocatechuate and benzoate as inducer-substrates are described in Fig. 2. In extracts of cells induced under varying conditions, strict proportionality was maintained over a wide range 


\title{
Table 4. Enzyme activities in R. mucilaginosa wild-type and strain PCA40 after growth on $10 \mathrm{mM}-\mathrm{glucose}$ in the presence of $20 \mathrm{m \textrm {M }}$-protocatechuate
}

\begin{abstract}
Organisms were grown to exponential phase at the expense of glucose, harvested by centrifugation, washed with physiological saline, and transferred to media containing $10 \mathrm{~mm}$-glucose and $20 \mathrm{~mm}$ protocatechuate. The initial cell density in the medium was adjusted to $5 \times 10^{5}$ organisms $/ \mathrm{ml}$ and cultures were incubated at $30^{\circ} \mathrm{C}$. After $18 \mathrm{~h}$, cultures were harvested and cell-free extracts prepared by sonication. The activity ratios reported represent the average of determinations on extracts prepared from three different cultures.
\end{abstract}

\section{Enzyme}

4-Hydroxybenzoate 3-mono-oxygenase

Protocatechuate 3,4-dioxygenase

3-Carboxymuconate cyclase

3-Carboxymuconolactone hydrolase

$\overbrace{\text { Wild type }}^{\text {Activity ratio }} \begin{array}{cc}\text { Strain PCA40 } \\ <0.006^{*} & <0.006 \\ 0.49 & <0.009 \\ 2.76 & 3.50 \\ 2.20 & 1.50\end{array}$

* Lower limit of detection.

of activities between the levels of 3-carboxymuconate cyclase, 3-carboxymuconolactone hydrolase and 3-oxoadipate CoA-transferase. These three enzymes therefore probably constitute a co-ordinately controlled block. The activities of the first two enzymes of the protocatechuate pathway, 4-hydroxybenzoate 3-mono-oxygenase and protocatechuate 3,4dioxygenase, did not exhibit this proportionality, both being more susceptible to catabolite repression than those enzymes constituting the co-ordinate block; they were thus believed to be independently controlled.

\section{Patterns of enzyme induction in mutants specifically blocked in the protocatechuate pathway}

Four independently isolated mutants of $R$. mucilaginosa were studied. Strains PHBI and PHB3 had lost the ability to grow on $p$-hydroxybenzoate while retaining the ability to grow at the expense of protocatechuate. Strains PCA33 and PCA40 lacked the ability to grow on either $p$-hydroxybenzoate or protocatechuate. All strains were capable of normal growth with glucose as carbon source. Cultures of these mutant strains and of the wild type were induced in a medium containing $10 \mathrm{~mm}$-glucose and $20 \mathrm{~mm}$ - $p$-hydroxybenzoate. The concentration of glucose in the medium was monitored throughout the period of induction and the cultures harvested when between 60 and $70 \%$ of the glucose had been utilized. Extracts were prepared as described in Methods.

Strains PCA33 and PCA40 lacked the ability to synthesize protocatechuate 3,4-dioxygenase (Table 3) while retaining the ability to synthesize all the other enzymes of the pathway. With the exception of the low 4-hydroxybenzoate 3-mono-oxygenase activity observed with strain PCA33, other enzyme levels were comparable to those obtained with the wild type under similar conditions; uninduced levels in these mutants were also strictly comparable to those observed for the wild-type strain.

As a consequence of the absence of protocatechuate 3,4-dioxygenase, neither strain PCA33 nor PCA40 could synthesize 3-carboxymuconate or subsequent intermediates of the protocatechuate pathway from $p$-hydroxybenzoate. Hence the observed induction of enzymes responsible for the conversion of 3-carboxymuconate to 3-oxoadipate suggested that either $p$-hydroxybenzoate or protocatechuate was acting as inducer for these enzymes.

Strains PHBI and PHB3 grown with $p$-hydroxybenzoate and glucose lacked the enzyme 4-hydroxybenzoate 3-mono-oxygenase (Table 3 ) while containing levels of other enzymes 
comparable to those observed in the wild-type strain. In this case, because neither strain was capable of synthesizing protocatechuate or subsequent intermediates on the pathway, $p$-hydroxybenzoate itself must have acted as inducer for all of the enzymes operative in the pathway.

In a further attempt to confirm the identity of the inducer(s) of the enzymes of the protocatechuate pathway, enzyme analyses were performed on extracts of both strain PCA4O and the wild type after induction in a medium containing $10 \mathrm{~mm}$-glucose and $20 \mathrm{~mm}$-protocatechuate (Table 4). Both strains exhibited negligible activities for 4-hydroxybenzoate 3-mono-oxygenase, confirming that this enzyme was induced by its substrate, $p$-hydroxybenzoate. However, in extracts of strain PCA4O, although protocatechuate 3,4-dioxygenase was absent and hence no intermediates after protocatechuate could have been formed, levels of 3-carboxymuconate cyclase and 3-carboxymuconolactone hydrolase comparable to those found in extracts of the wild type were observed. These data indicated that protocatechuate was also capable of acting as an inducer for the cyclase and hydrolase enzymes.

\section{Examination of analogues as inducers of the 3-oxoadipate pathway}

In view of the induction of enzymes of the 3-oxoadipate pathway by either p-hydroxybenzoate or protocatechuate, the inductive properties of several analogues of these intermediates were examined in an attempt to specify the chemical requirements of the inducing molecule more precisely. A prerequisite for the use of such analogues as gratuitous inducers was that they should not inhibit the growth of $R$. mucilaginosa on Io mM-glucose when utilized at concentrations up to $2.5 \mathrm{~mm}$, nor should they be metabolized by the organism. Of the analogues available, ethyl $p$-hydroxybenzoate and piperonylate $(3,4$-methylenedioxybenzoate) were toxic to the organism and were not further examined. Other analogues used satisfied the criteria described above. The protocatechuate analogues 3-hydroxy-4-methylbenzoate (Cánovas, Wheelis \& Stanier, 1968) and catechol-4-sulphonate both failed to induce any of the enzymes of the protocatechuate pathway above the activities found in extracts of uninduced glucose controls, either in the wild-type strain or in mutant strain PCA40. Similarly, the $p$-hydroxybenzoate analogues anisate (4-methoxybenzoate), $p$-fluorobenzoate, $p$-chlorobenzoate and phenolsulphonate failed to elicit induction of the enzymes when present at $2 \mathrm{~mm}$ in cultures growing with Io mM-glucose.

\section{DISCUSSION}

Rhodotorula mucilaginosa was unable to utilize catechol or its common precursors, either in the presence or absence of glucose, substantiating earlier observations by Cain (1969) and Halsall (I97I) with this yeast. This inability of the organism to grow with substrates known to act as inducers for the catechol pathway in other fungi, e.g. catechol and anthranilate (Halsall, I97I), together with the total absence of enzymes specific to the catechol pathway in any of the cell-free extracts examined, strongly suggests that there is no operative pathway for the degradation of catechol in this organism. This fact should be reflected in the regulatory pattern of the 3-oxoadipate pathway, as this may now be regarded as a single catabolic sequence for protocatechuate degradation rather than a system of convergent analogous sequences as in other micro-organisms.

Conclusions concerning the regulation of synthesis of enzymes of the protocatechuate pathway in $R$. mucilaginosa are summarized in Fig. 3. Three successive inductive events permitted the synthesis of the five enzymes which convert $p$-hydroxybenzoate to 3 -oxoadipyl-CoA: (i) induction of 4 -hydroxybenzoate 3-mono-oxygenase, (ii) induction of proto- 


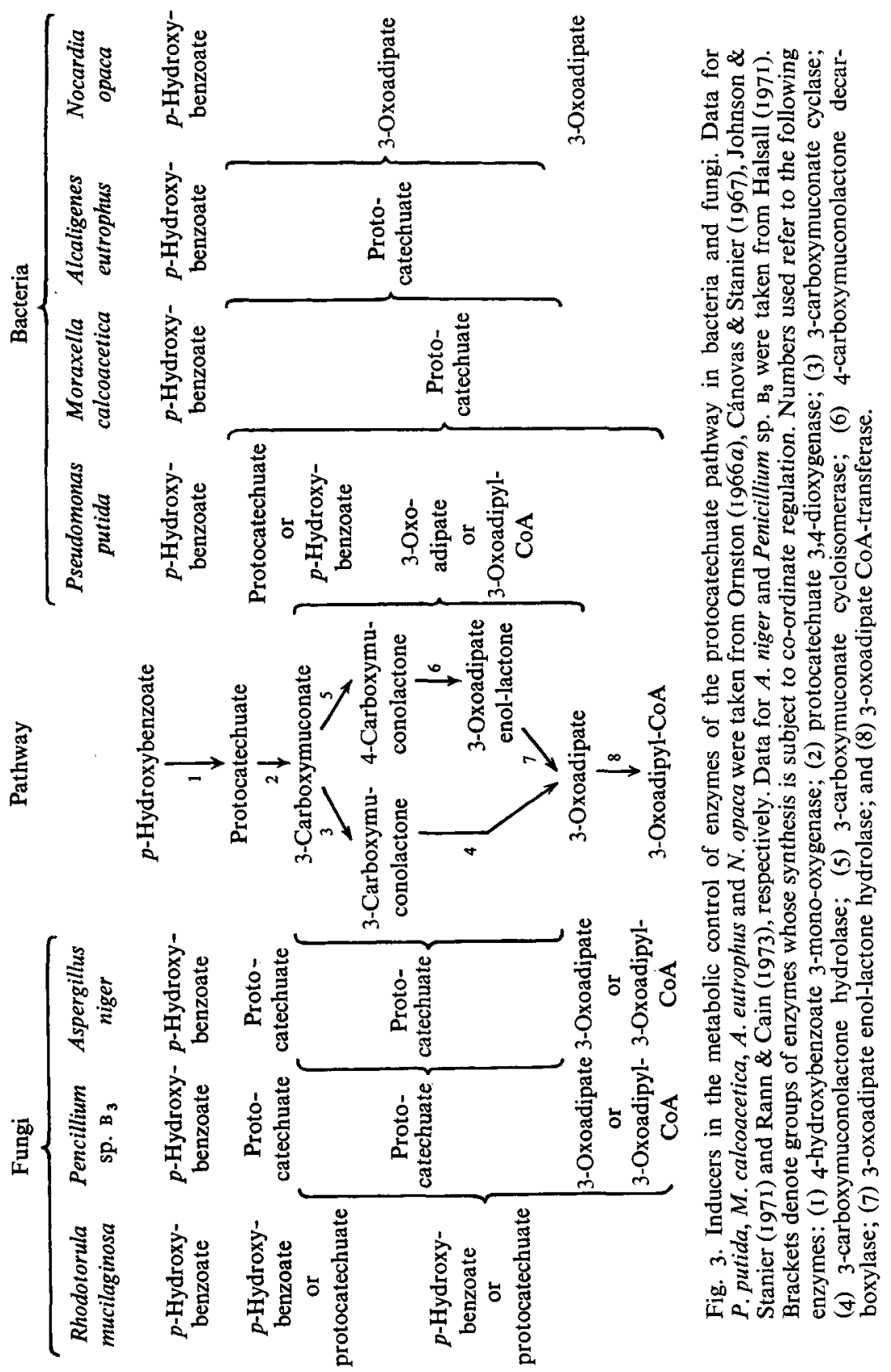


catechuate 3,4-dioxygenase and finally (iii) co-ordinate induction of 3-carboxymuconate cyclase, 3-carboxymuconolactone hydrolase and 3-oxoadipate CoA-transferase. The first enzyme of the sequence, 4 -hydroxybenzoate 3-mono-oxygenase, was independently regulated and induced by its substrate $p$-hydroxybenzoate. This was inferred from the observation that the enzyme was induced by growth with its substrate, $p$-hydroxybenzoate, but not with its product, protocatechuate (Table 2). The remaining enzymes of the sequence were induced by either $p$-hydroxybenzoate or protocatechuate, both of which appeared to function equally efficiently as inducers. Protocatechuate 3,4-dioxygenase was independently regulated while the remaining three enzymes were induced as a co-ordinate block. Inductive functions were ascribed to both $p$-hydroxybenzoate and protocatechuate because growth of the mutant strains PHBI and PHB3 in the presence of $p$-hydroxybenzoate elicited synthesis of the remaining enzymes of the sequence, although neither strain was capable of synthesizing either protocatechuate or subsequent intermediates on the pathway from $p$-hydroxybenzoate. Similarly, growth of strains PCA33 and PCA4O in the presence of protocatechuate elicited the synthesis of enzymes of the 3-carboxymuconate co-ordinate block, although as a consequence of their inability to synthesize protocatechuate 3,4-dioxygenase neither strain was capable of synthesizing 3-carboxymuconate or subsequent intermediates from protocatechuate. The inability of the inducer system in this yeast to distinguish between $p$-hydroxybenzoate and protocatechuate did not extend to the $p$-hydroxybenzoate analogues $p$-fluorobenzoate, anisate, $p$-chlorobenzoate and phenolsulphonic acid, or the protocatechuate analogues 3-hydroxy-4-methylbenzoate and catechol-4-sulphonate; none of these analogues was able to function as a gratuitous inducer.

The activities of enzymes of the protocatechuate pathway in extracts of uninduced cultures of $R$. mucilaginosa were uncommonly high, a phenomenon also observed with other fungi (Gross et al. 1956; Cain et al. 1968; Halsall, 1971). In contrast to the uninduced levels observed in Pseudomonas putida and Moraxella calcoacetica (Ornston, I966a, Cánovas et al. I968), representing at most about $2 \%$ of the fully induced activities, the uninduced levels in $R$. mucilaginosa were between 5 and $10 \%$ of the fully induced levels for protocatechuate 3,4-dioxygenase, 3-carboxymuconolactone hydrolase and 3-oxoadipate CoA-transferase and sometimes up to $40 \%$ for 3 -carboxymuconate cyclase. The mono-oxygenase mediating conversion of $p$-hydroxybenzoate to protocatechuate was the only enzyme in the sequence to be completely repressed after growth on glucose. Similar results have been obtained with Aspergillus niger, Trichoderma viride, Penicillium spinulosum and Aureobasidium pullulans (Cain et al. 1968; Haslall, I971), although the unusually high uninduced 3-carboxymuconate cyclase activity reported here is comparable only to earlier results obtained with $R$. mucilaginosa (Halsall, 197I). Because protocatechuate can be formed endogenously in $M$. calcoacetica (Cánovas et al. 1968) and $N$. crassa (Gross et al. 1956) by the action of the inducible enzyme 3-dehydroshikimate dehydratase (EC. 4.2.I.-) on 3-dehydroshikimate, an early intermediate in the biosynthesis of the aromatic amino acids (Gross, 1958), the enzymes of the (catabolic) protocatechuate pathway are potentially subject to internal induction. High basal enzyme activities may, therefore, provide a means of metabolizing the endogenous protocatechuate and so prevent it from reaching concentrations which would be sufficient to elicit maximum induction of those enzymes for which it serves as inducer. This hypothesis was substantiated in $M$. calcoacetica by the observation that when protocatechuate 3,4-dioxygenase was destroyed by mutation the normal metabolic control over the endogenously formed inducer was abolished, and mutants became capable of pseudo-constitutive synthesis of all enzymes under the control of protocatechuate. Data obtained with mutant strains of $R$. mucilaginosa lacking the ability to synthesize proto- 
catechuate 3,4-dioxygenase (Table 3) indicated, however, that pseudo-constitutive synthesis was not occurring in this way. The high uninduced levels observed in this yeast indicate that fine control of the appropriate enzymes may be exercised at a biochemical rather than at a genetic level.

The data now available make it possible to draw a comparison between regulation of the protocatechuate branch of the 3-oxoadipate pathway in $R$. mucilaginosa and other genera of both bacteria and fungi (Fig. 3). In A. niger and Penicillium sp. $\mathrm{B}_{3}$ the product of the co-ordinately controlled enzyme blocks of both catechol and protocatechuate branches of the pathway is 3-oxoadipate; thus co-ordinate control ceases at the point of convergence of these branches, and the first common intermediate compound in fungi, 3-oxoadipate, acts as an inducer for the enzyme responsible for its breakdown. In R. mucilaginosa, however, the extent of co-ordinate control is somewhat greater than in other fungi (Fig. 3), encompassing the three enzymes responsible for the conversion of 3 -carboxymuconate to 3-oxoadipyl-CoA. The extension of the co-ordinate block to include 3-oxoadipate CoA-transferase possibly reflects the absence of a catechol-degrading pathway in this yeast, thus eliminating the necessity for special control steps to accommodate the converging catabolic sequence.

We gratefully acknowledge support for this work by Science Research Council Grant B/RG/3509 to Dr R. B. Cain.

\section{REFERENCES}

Ainsworth, A. T. \& Kirby, G. W. (I968). Stereochemistry of $\beta$-carboxy and $\beta$-hydroxymethyl-muconic derivatives. Journal of the Chemical Society, 1483-1487.

Bardhan, J. C. (1936). Studies in the sterol-oestone group. I. A synthesis of $3^{\prime}-k e t o-3: 4$-dihydro-I:2 cyclopentano phenanthrene. Journal of the Chemical Society, 1848-185 I.

CAIN, R. B. (1969). The regulation of enzymes of aromatic-ring fission in fungi: organisms using only the protocatechuate pathway. Biochemical Journal $114,76 \mathrm{P}$.

Cain, R. B., Bilton, R. F. \& Darrah, J. A. (I968). The metabolism of aromatic acids by micro-organisms. Metabolic pathways in the fungi. Biochemical Journal 108, 797-828.

Cánovas, J. L. \& Stanier, R. Y. (1967). Regulation of the enzymes of the $\beta$-ketoadipate pathway in $M o r-$ axella calcoacetica. I. General aspects. European Journal of Biochemistry r, 289-300.

Cánovas, J. L., Wheelis, M. L. \& StanieR, R. Y. (I968). Regulation of the enzymes of the $\beta$-ketoadipate pathway in Moraxella calcoacetica. II. The role of protocatechuate as inducer. European Journal of Biochemistry 3, 293-304.

Cook, K. A. (1974). Regulation of aromatic metabolism in the fungi: selection of mutants of the yeast Rhodotorula mucilaginosa with nystatin. Journal of General Microbiology 85, 29-36.

Cook, K. A. \& Sorger, G. J. (1969). The metabolic control of nitrite reductase in Neurospora crassa. Biochimica et biophysica acta $\mathbf{1 7 7}, 412-420$.

Glock, G. E. \& MCLeAN, P. (1953). Further studies on the properties and assay of glucose 6-phosphate dehydrogenase and gluconate 6-phosphate dehydrogenase. Biochemical Journal 55, 400-406.

Gornall, A. G., Bardawill, C. H. \& David, M. A. (I949). Determination of serum proteins by means of the Biuret reaction. Journal of Biological Chemistry 177, 75I-766.

Gross, S. R. (1958). The enzymic conversion of 5 -dehydroshikimic acid to protocatechuic acid. Journal of Biological Chemistry $\mathbf{2 3 3}$, I I46-I I 5 I.

Gross, S. R., GAFFord, R. D. \& TATUM, E. L. (1956). The metabolism of protocatechuic acid by Neurospora. Journal of Biological Chemistry 219, 781-795.

Halsall, B. E. (197I). Metabolism of aromatic-ring compounds and its regulation in fungi. Ph.D. thesis, University of Newcastle.

Halsall, B. E., Darrah, J. A. \& Cain, R. B. (I969). The regulation of enzymes of aromatic-ring fission in fungi: organisms using both catechol and protocatechuate pathways. Biochemical Journal II4, 75 P. 
JOHNSON, B. F. \& STANIER, R. Y. (I97I). Regulation of the $\beta$-ketoadipate pathway in Alcaligenes eutrophus. Journal of Bacteriology I07, 476-485.

KATAGIRI, M. \& HAYAISHI, O. (1957). Enzymatic degradation of $\beta$-ketoadipic acid. Journal of Biological Chemistry 226, 439-448.

KemP, M. B. \& HEGEMAN, G. D. (1968). Genetic control of the $\beta$-ketoadipate pathway in Pseudomonas aeruginosa. Journal of Bacteriology 96, I488-1499.

LipmanN, F. \& TUTTLE, L. C. (1945). Specific micromethod for the determination of acylphosphates. Journal of Biological Chemistry 159, $2 \mathrm{I}-28$.

NoRTH, J. \& LEWIS, D. (1973). Variation in the basal level of alkaline phosphatase in Coprinus lagopus wildtype strains. Genetical Research 22, I8 I-I 85 .

ORNSTON, L. N. (I $966 a$ ). The conversion of catechol and protocatechuate to $\beta$-ketoadipate by Pseudomonas putida. IV. Regulation. Journal of Biological Chemistry 24I, 3800-3810.

ORNSTON, L. N. (1966 b). The conversion of catechol and protocatechuate to $\beta$-ketoadipate by Pseudomonas putida. III. Enzymes of the catechol pathway. Journal of Biological Chemistry 24I, 3795-3799.

RANN, D. L. \& CAIN, R. B. (1969). The regulation of the enzymes of aromatic-ring fission in an actinomycete. Biochemical Journal $1 \mathbf{1 4}_{4}, 77 \mathrm{P}$.

RANN, D. L. \& CAIN, R. B. (1973). Regulation of the enzymes of aromatic-ring fission in the genus Nocardia. Biochemical Society Transactions I, 658-66I.

Robert-Gero, M., PoIret, M. \& Stanier, R. Y. (1969). The function of the $\beta$-ketoadipate pathway in Pseudomonas acidovorans. Journal of General Microbiology 57, 207-21 4.

Simon, E. J. \& Shemin, D. (1953). The preparation of S-succinyl coenzyme A. Journal of the American Chemical Society 75, 2520.

Stadtman, E. R. (1957). Preparation and assay of acyl CoA and other thiolesters: use of hydroxylamine. In Methods in Enzymology, vol. 3, pp. 931-94I. Edited by S. P. Colowick and N. O. Kaplan. New York: Academic Press.

Stanier, R. Y. (1968). Biochemical and immunological studies on the evolution of a metabolic pathway in bacteria. In Chemotaxonomy and Serotaxonomy, Systematics Association special volume No. 2, pp. 20I-225. Edited by J. G. Hawkes. New York: Academic Press. 